\title{
SINTESIS POLI ASAM LAKTAT BERBOBOT MOLEKUL RENDAH MEMAKAI KATALIS STANNUM
}

\author{
Ricson P. Hutagaol, Lany Nurhayati dan Jessica Analy \\ Fakultas MIPA Universitas Nusa Bangsa, Bogor ${ }^{1,2)}$ \\ Jl. K. H. Sholeh Iskandar, Cimanggu, Tanah Sareal-Bogor 16166 \\ email : nusabangsa@unb.ac.id
}

\author{
ABSTRACT \\ Synthesis Of Poly Lactic Acid Catalyst To Use Low-molecular-weight \\ Using Stannum Catalyst \\ By. Ricson P. Hutagaol, Lany Nurhayati and Jessica Analy
}

\begin{abstract}
Poly lactic acid is a polyester that can be produced using raw materials of renewable natural resources such as starch and cellulose. These polymers can be degraded by hydrolysis process in the body and excreted within a few months. This polymer is not toxic and has been widely used in medical field such as for implants and medium in drug delivery systems (Drug Delivery System, DDS). Low molecular weight polymers that accelerate the degradation and the increasing concentration of drug detachment, while polymers with high molecular weight have a lower solubility so degraded more slowly. Polymerization process is affected by the solvent used, reaction temperature, time of agitation and catalyst used. Stanum $(\mathrm{Sn})$ is the best catalyst is used to obtain polymers at relatively low temperatures. Synthesis is done by mixing the lactic acid with xylene and Stanum as a catalyst. Variation Stanum catalyst used, ie 0\%, $1.0 \%, 2.0 \%, 3.0 \%$, and $4.0 \%$. Reacted in a reactor at a temperature of $140{ }^{\circ} \mathrm{C}$ for 14 hours. Added chloroform, filtered and added to cold methanol. The precipitate was filtered and washed with cold methanol. The rst deposits exposed in the air and then heated in an oven at $80^{\circ} \mathrm{C}$. Based on the results of the study, obtained the concentration of $2 \%$ was an optimum concentration of Sn is used to produce 4.55 grams of poly lactic acid of 20 grams of lactic acid with a molecular weight of $23289.83 \mathrm{~g} / \mathrm{mol}$ and the residue Stanum at 175.174 ppm.
\end{abstract}

Keywords : Poly lactic acid, polikondensasu, catalyst, sanum.

\begin{abstract}
ABSTRAK
Poli asam laktat merupakan poliester yang dapat diproduksi menggunakan bahan baku sumber daya alam terbarukan seperti pati dan selulosa. Polimer ini dapat terdegradasi dengan proses hidrolisis dalam tubuh dan terekskresi dalam waktu beberapa bulan. Polimer ini tidak meracuni tubuh dan telah banyak digunakan dalam bidang kedokteran seperti untuk implan dan medium dalam sistem penyampaian obat (Drug Delivery System, DDS). Bobot molekul polimer yang rendah mempercepat degradasi dan naiknya konsentrasi lepasan obat, sedangkan polimer dengan bobot molekul tinggi memiliki kelarutan yang lebih rendah sehingga terdegradasi lebih lambat. Proses polimerisasi dipengaruhi oleh pelarut yang digunakan, suhu reaksi, waktu pengocokan dan katalis yang digunakan. Stanum (Sn) merupakan katalis yang paling baik digunakan untuk mendapatkan polimer pada suhu yang relatif rendah. Sintesis dilakukan dengan mencampur asam laktat dengan xilena dan stanum sebagai katalis. Dilakukan variasi katalis stanum yang digunakan, yaitu $0 \% ; 1,0 \%$ ; $2,0 \% ; 3,0 \%$; dan 4,0\%. Direaksikan dalam reaktor pada suhu $140{ }^{\circ} \mathrm{C}$ selama 14 jam. Ditambahkan kloroform, disaring dan ditambahkan metanol dingin. Endapan disaring dan dicuci dengan metanol dingin. Sisa endapan dianginkan di udara lalu dipanaskan dalam oven pada suhu $80{ }^{\circ} \mathrm{C}$. Berdasarkan hasil penelitian, didapat konsentrasi $2 \%$ merupakan konsentrasi Sn yang paling optimum digunakan untuk menghasilkan 4,55 gram poli asam laktat dari 20 gram asam laktat dengan bobot molekul 23289,83 g/mol dan residu stanum sebesar $175,174 \mathrm{ppm}$.
\end{abstract}

Kata kunci : Poli asam laktat, polikondensasu, katalis, stanum.

\section{PENDAHULUAN}

Poli asam laktat nerupakan poliester alifatik yang dapat diproduksi dari sumber daya alam terbarukan seperti asam laktat. Poli asam laktat memiliki aplikasi yang baik dalam bidang kesehatan dan industri kemasan (Lee et al, 2005).

Poli asam laktat dapat didegradasi dengan degradasi abiotik, yaitu hidrolisis sederhana dari ikatan ester tanpa dibutuhkan enzim untuk mengkatalisasinya. Pada tahap kedua proses degradasi, enzim akan mendegradasi oligomer yang tersisa hingga mineralisasi akhir (Avérous, 2008).

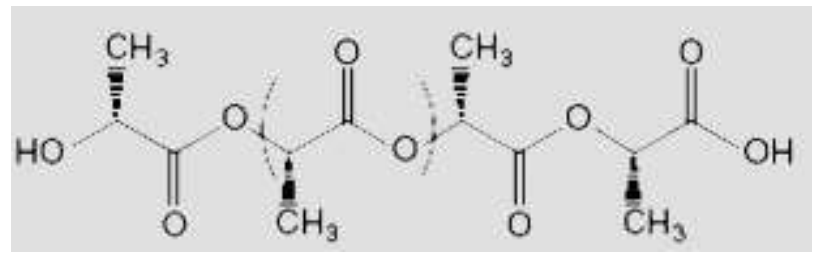

Gambar 1. Struktur Molekul Poli Asam Laktat 
Polimer ini tidak meracuni tubuh (biocompatible) dan telah banyak digunakan dalam bidang kedokteran seperti untuk implan dan media dalam sistem penyampaian obat (Drug Delivery System, DDS) (Avérous, 2008).

Nurhayati (2006) menyatakan bahwa bobot molekul polimer yang rendah mempercepat degradasi dan naiknya konsentrasi lepasan obat, sedangkan polimer dengan bobot molekul tinggi mempunyai kelarutan yang lebih rendah sehingga proses degradasi lebih lambat. Faktor-faktor yang mempengaruhi bobot molekul poli asam laktat dalam proses pembuatannya, diantaranya adalah suhu, katalis, dan waktu polimerisasi (Ajioka et al, 1995).

Proses polimerisasi dengan kondensasi memiliki kelemahan yaitu lamanya waktu yang diburtuhkan dalam proses tersebut. Proses polimerisasi dapat dilakukan pada waktu yang lebih singkat dengan mengkondisikan reaktor dalam keadaan vakum (Proikakis, 2002).

Bobot molekul polimer yang dihasilkan tergantung dari katalis yang digunakan. Senyawa stanum merupakan katalis yang paling baik untuk memproduksi poli asam laktat dalam suhu relatif rendah $\left(130^{\circ} \mathrm{C}\right)$ (Ajioka et al, 1995).

Melihat fungsi poli asam laktat sebagai DDS, maka perlu dihasilkan poli asam laktat yang memiliki bobot molekul rendah, yaitu sekitar 20000. Waktu polimerisasi yang lama dan penggunaan tekanan vakum mengakibatkan kurang efektifnya produksi poli asam laktat dalam skala industri. Jenis dan konsentrasi katalis yang digunakan akan mempengaruhi jumlah dan bobot molekul polimer yang dihasilkan.

Tujuan penelitian ini adalah untuk memperoleh poli asam laktat dengan bobot molekul rendah agar dapat dimanfaatkan sebagai medium dalam sistem penyampaian obat dengan waktu polimerisasi lebih singkat dan tekanan normal. Serta menentukan konsentrasi katalis yang tepat, agar residu katalis tidak meracuni tubuh.

Penelitian ini bertujuan untuk mendapatkan poli asam laktat berbobot molekul rendah yang dapat diaplikasikan sebagai medical grade dengan penambahan katalis stanum, sehingga waktu yang diperlukan semakin sedikit.

Poli asam laktat (polylactic acid/PLA) memiliki berbagai fungsi, diantaranya sebagai plastik biodegradabel dan dalam bidang medis sebagai medium dalam sistem penyampaian obat karena sifatnya yang dapat didegradasi oleh tubuh (Nurhayati, 2006). Poli asam laktat dapat dihasilkan dari reaksi polimerisasi asam laktat. Menurut Proikakis et al (2002), reaksi polimerisasi asam laktat dapat dilakukan dengan dua cara, yaitu polimerisasi langsung dari asam laktat dan polimerisasi pembukaan rantai dari laktida. Sintesis poli asam laktat melalui kondensasi langsung dari monomer asam laktat diketahui memberikan bobot molekul rata-rata kurang dari $1,6 \times 10^{4}$.

Keberadaan gugus hidroksil dan karboksil pada asam laktat membuat asam laktat dapat diubah secara langsung menjadi poliester melalui reaksi polikondensasi konvensional. Dalam reaksi ini diperlukan waktu yang lama. Polikondensasi azeotrop merupakan metode untuk memperoleh poli asam laktat tanpa penggunaan chain extender (Garlotta, 2002). Polikondensasi poli asam laktat memerlukan waktu yang lama, yaitu 30-40 jam (Garlotta, 2002). Salah satu cara untuk mengurangi lamanya waktu yang dibutuhkan untuk polimerisasi adalah penggunaan tekanan. Polimerisasi langsung poli asam laktat pada suhu hingga $180^{\circ} \mathrm{C}$ pada keadaan vakum menghasilkan reaksi yang cepat (Proikakis, 2002). Proses polimerisasi dipengaruhi oleh pelarut yang digunakan, suhu reaksi, waktu pengocokan dan katalis yang digunakan.

Dalam polimerisasi langsung dengan kondensasi, asam L- laktat dan asam D-laktat terdapat secara acak dalam polimer, sedangkan dalam polimerisasi dengan pembukaan cincin laktida, dua monomer optik aktif ini terdapat secara teratur dan berpasangan (Ajioka et al, 1995). Menurut Dutkiewicz et al (2003), suhu polimerisasi tidak boleh lebih dari $140^{\circ} \mathrm{C}$, karena dalam suhu lebih tinggi akan terjadi racemization. Recemization adalah konversi sebagian bentuk dari suatu enantiomer ke bentuk lainnya.

Menurut Ajioka et al (1998), terdapat beberapa jenis katalis yang dapat digunakan dalam polimerisasi poli asam laktat dengan polikondensasi, seperti asam proton, logam, logam oksida, logam halida, dan garam asam organik dari logam. Bobot molekul poli asam laktat yang dihasilkan tergantung dari katalis yang digunakan. Senyawa stanum merupakan senyawa yang paling baik digunakan untuk polimerisasi pada suhu relatif rendah $\left(130^{\circ} \mathrm{C}\right)$.

Untuk mengetahui jumlah katalis yang digunakan, maka diperlukan penelitian untuk menentukan jumlah optimum katalis yang digunakan. Karena logam yang digunakan sebagai katalis berbahaya bagi manusia, maka harus dipastikan jumlah katalis yang tertinggal dalam poli asam laktat setelah proses sintesis.

Hipotesis dari penelitian ini adalah reaksi polimerisasi dengan kondensasi dapat menghasilkan poli asam laktat dengan bobot molekul rendah, jumlah katalis yang digunakan 
akan mempengaruhi karakteristik poli asam laktat yang dihasilkan.

\section{METODE PENELITIAN}

\section{Bahan dan Alat}

Bahan yang digunakan dalam sintesis ini adalah asam laktat (90\%), xilena, logam stanum, kloroform dan metanol.

Alat yang digunakan dalam sintesis ini adalah neraca analitik, Dean Stark Trap (Gambar 4), labu berleher tiga, mantel heater, vacuum pump, filter unit, oven, kertas saring Whatman No. 40, piala gelas dan gelas ukur.

\section{Prosedur}

Sintesis dilakukan dengan mencampur 20 gram asam laktat dengan $200 \mathrm{ml}$ xilena dan stanum sebagai katalis. Dilakukan variasi katalis stanum yang digunakan, yaitu $0 \%(\mathrm{~b} / \mathrm{b}) ; 1 \%(\mathrm{~b} / \mathrm{b}) ; 2 \%$ (b/b); $3 \%$ (b/b); dan $4 \%$ (b/b). Direaksikan dalam reaktor, berupa Dean Stark Trap yang dihubungkan dengan labu berleher tiga, lalu dipanaskan pada suhu $140{ }^{\circ} \mathrm{C}$ selama 14 jam untuk melepaskan air. Larutan yang tertinggal dalam labu kemudian ditambahkan $300 \mathrm{ml}$ kloroform lalu disaring. Ke dalam filtrat ditambahkan $1100 \mathrm{ml}$ metanol dingin sedikit demi sedikit sambil diaduk. Endapan disaring dan dicuci dengan metanol dingin. Sisa endapan dikeringudarakan lalu dipanaskan dalam oven pada suhu $80{ }^{\circ} \mathrm{C}$ selama 2 jam. Dilakukan pengujian untuk poli asam laktat yang dihasilkan, meliputi identifikasi dengan FTIR, penentuan bobot molekul dengan penetapan viskositas cara Ostwald, dan penetapan residu katalis stanum dengan AAS.

\section{HASIL DAN PEMBAHASAN}

\section{A. Jumlah Poli Asam Laktat yang dihasilkan}

Dari sintesis yang dilakukan dengan variasi konsentrasi stanum sebagai katalis, dihasilkan poli asam laktat dengan kuantitas ditunjukan pada Tabel 1.

Dari hasil penelitian yang telah dilakukan, untuk konsentrasi katalis $0 \%$ tidak didapatkan endapan poli asam laktat. Pada akhir proses reaksi didapatkan larutan yang berwarna kekuningan. Hal ini disebabkan asam laktat mengalami pemanasan di atas suhu titik didihnya yaitu $122^{\circ} \mathrm{C}$. Sedangkan pada konsentrasi katalis lain, tidak didapatkan larutan yang berwarna kekuningan. Hal ini disebabkan oleh sebagian asam laktat telah bereaksi menjadi poli asam laktat dengan titik didih di atas asam laktat.

Penggunaan $1 \%$ stanum dalam penelitian ini tidak menghasilkan endapan poli asam laktat pada akhir reaksi. Pada akhir proses polimerisasi, diperoleh larutan keruh dengan adanya koloid berwarna putih dan di dasar labu terdapat gel kental yang transparan. Lee et al (2005) menyatakan bahwa gel kental transparan merupakan ciri oligomer poli asam laktat. Saat dilakukan filtrasi tidak didapatkan endapan pada kertas saring, sehingga filtrat masih keruh. Berdasarkan pengamatan yang dilakukan, dapat disimpulkan bahwa proses polimerisasi belum berlangsung dengan sempurna, dimana hanya terbentuk polimer dengan ukuran dan bobot molekul yang rendah.

Hal-hal yang mungkin menyebabkan tidak terbentuknya poli asam laktat pada konentrasi $1 \%$ stanum sebagai katalis, diantaranya tekanan. Suhu, dan waktu polimerisasi.

Pada konsentrasi katalis $2 \%$, didapatkan poli asam laktat yang paling optimum. Setelah proses polimerisasi didapatkan endapan poli asam laktat di sekeliling labu berleher tiga. Saat diendapkan kembali dengan penambahan metanol, terbentuk endapan putih yang terpisah dari larutannya saat difiltrasi dengan kertas saring Whatman nomor 40.

Poli asam laktat yang dihasilkan dari polimerisasi asam laktat dengan $3 \%$ katalis berjumlah lebih sedikit dari polimer yang dihasilkan dengan $2 \%$ katalis. Hal ini menandakan jumlah katalis yang ditambahkan sudah terlalu banyak, sehingga jumlah sisi aktif katalis terisi dengan monomer asam laktat semakin banyak. Hal ini mengakibatkan monomer asam laktat habis sehingga saat sisi aktif katalis akan mengikat monomer asam laktat yang lain, asam laktat yang tersedia dalam larutan telah habis. Sehingga hanya akan dihasilkan polimer dengan bobot molekul yang rendah.

Saat digunakan $4 \%$ katalis dalam reaksi polimerisasi, tidak didapatkan poli asam laktat yang terbentuk dari reaksi. Larutan yang didapat sedikit keruh, tapi kurang keruh dibandingkan dengan menggunakan $1 \%$ katalis. Hal ini menandakan katalis yang ditambahkan telah terlalu banyak.

\section{B. Identifikasi dengan FTIR}

Dari analisis yang telah dilakukan terhadap poli asam laktat hasil sintesis, diketahui bahwa poli asam laktat yang dihasilkan melalui sintesis dan poli asam laktat standar memiliki kemiripan pada 
puncak spektrum infra merah seperti ditunjukan pada gambar 2 .

1. Puncak pada bilangan gelombang $3000-2990$ $\mathrm{cm}^{-1}$ yang disertai dengan puncak pada bilangan gelombang $1770-1750 \mathrm{~cm}^{-1}$ merupakan ciri ikatan asam karboksilat.

2. Puncak pada bilangan gelombang $1770-1750$ $\mathrm{cm}^{-1}$, merupakan ciri ikatan $\mathrm{C}=\mathrm{O}$, disertai dengan puncak pada bilangan gelombang 1300 - $1000 \mathrm{~cm}^{-1}$ yang merupakan ciri ikatan ester.

3. Puncak pada bilangan gelombang $3000-2700$ $\mathrm{cm}^{-1}$ merupakan ciri ikatan C-H.

4. Puncak pada bilangan gelombang $1135-1125$ $\mathrm{cm}^{-1}$, merupakan ciri ikatan $\mathrm{C}-\mathrm{O}$.

Hal yang menyebabkan ketidakmiripan pada spektrum IR dari poli asam laktat standar dengan poli asam laktat hasil sintesis adalah, preparasi sampel yang berbeda. Standar poli asam laktat yang digunakan tidak dapat digerus dengan $\mathrm{KBr}$ seperti yang dilakukan pada poli asam laktat hasil sintesis yang masih berbentuk serbuk, dikarenakan sudah berbentuk bijih plastik.

\section{Penentuan Bobot Molekul dengan Penetapan Viskositas cara Ostwald}

Nasiri (2008) mengungkapkan bahwa dengan menggunakan pelarut kloroform pada suhu $30^{\circ} \mathrm{C}$, bobot molekul rata-rata poli asam laktat dapat dihitung menurut rumus Mark-Houwink, dengan metode yang dikembangkan oleh Schultz Blaske, yaitu :

$$
\begin{aligned}
& \mathrm{Mw}=\frac{[\eta]}{\mathrm{K}}^{(\mathrm{l} / \mathrm{a})} \\
& {[\eta]=\frac{\eta_{1}}{c\left(1+k s b \cdot \eta_{L}\right)}} \\
& \eta_{t}-\frac{\eta_{-}}{\eta_{1}}=\frac{\eta}{\eta_{1}}=\frac{t_{\text {robein }}}{t_{\text {glarus }}}-1
\end{aligned}
$$

dimana, Mw : Bobot molekul rata-rata

$$
\begin{array}{ll}
\mathrm{a} & : 0.777 \\
\mathrm{~K} & : 0.0131 \mathrm{ml} / \mathrm{g} \\
\mathrm{k}_{\mathrm{SB}} & : 0.302 \\
\mathrm{c} & : \text { konsentrasi dalam } \mathrm{g} / \mathrm{mL}
\end{array}
$$

Berdasarkan pengukuran yang dilakukan, didapatkan hasil sebagai berikut,

a. Konsentrasi stanum $2 \%$ : bobot molekul ratarata sebesar $23289,83 \mathrm{~g} / \mathrm{mol}$.

b. Konsentrasi stanum $3 \%$ : bobot molekul ratarata sebesar $7101,96 \mathrm{~g} / \mathrm{mol}$.

Dari hasil penelitian didapatkan bobot molekul yang berbeda nyata untuk konsentrasi stanum $2 \%$ dan $3 \%$. Hal ini diakibatkan pada saat jumlah katalis meningkat, maka sisi aktif katalis akan meningkat. Hal ini menyebabkan semakin banyak monomer asam laktat yang berikatan dengan sisi aktif katalis. Saat monomer asam laktat akan bereaksi untuk membentuk poli asam laktat dengan rantai yang lebih panjang, monomer asam laktat yang terdapat dalam larutan sudah habis. Sehingga hanya akan dihasilkan polimer dengan bobot molekul yang rendah.

\section{Kadar Stanum dengan Spektrofotometer Serapan Atom}

Dari pengukuran yang telah dilakukan terhadap poli asam laktat hasil sintesis, didapatkan hasil seperti pada Tabel 2.

Residu katalis yang terdapat dalam sampel jauh berkurang dibandingkan dengan jumlah stanum yang ditambahkan. Hal ini disebabkan katalis yang digunakan memiliki perbedaan sifat yang cukup nyata dengan poli asam laktat. Poli asam laktat memiliki parameter kelarutan $(\delta)$ sebesar 10,94, yang didapatkan berdasarkan perhitungan dengan rumus sebagai berikut :

$$
\delta=\frac{\rho . \Sigma E}{M}
$$

dimana, $\rho=$ massa jenis polimer

$$
\begin{aligned}
\Sigma \mathrm{E}= & \text { molar attraction constant } \\
& \left.\left((\text { cal.cm })^{3}\right)^{1 / 2} / \mathrm{mol}\right) \\
\mathrm{M}= & \text { Bobot molekul unit ulang } \\
& \text { polimer }
\end{aligned}
$$

Polimer dapat larut dalam pelarut yang memiliki perbedaan nilai parameter kelarutan $<2,0$. Maka poli asam laktat akan larut dalam xilena $(\delta=8,85)$ yang bercampur dengan kloroform $(\delta=9,21)$. Dengan parameter kelarutan sebesar 9,07 yang diperoleh berdasarkan perhitungan sebagai berikut, 


$$
\delta=\left(\delta_{1} \cdot \mathrm{X}_{1}\right)+\left(\delta_{2} \cdot \mathrm{X}_{2}\right)
$$

dimana,

$\delta_{1}=$ parameter kelarutan xilena

$\mathrm{X}_{1}=$ fraksi xilena dalam campuran

$\delta_{2}=$ parameter kelarutan kloroform

$\mathrm{X}_{2}=$ fraksi kloroform dalam campuran

Stanum yang berbentuk logam tidak larut dalam pelarut organik, sehingga campuran dapat dipisahkan dengan filtrasi. Setelah dipisahkan, poli asam laktat dalam filtrat dapat diendapkan kembali dengan penambahan metanol dalam jumlah banyak dengan parameter kelarutan sebesar 14,5.

Kelemahan reaksi polimerisasi dengan kondensasi adalah residu katalis yang tertinggal dalam jumlah yang cukup besar. Residu katalis dapat menyebabkan degradasi atau hidrolisis yang tidak terkontrol. Terlebih pada penggunaan poli asam laktat sebagai medium dalam sistem penyampaian obat, residu katalis akan meracuni tubuh. Residu katalis yang berlebih dapat dihilangkan dengan penambahan asam kuat seperti asam sulfat (Garlotta, 2002).

\section{KESIMPULAN DAN SARAN}

\section{A. Kesimpulan}

Jumlah stanum sebagai katalis dalam sintesis poli asam laktat dengan polikondensasi sangat mempengaruhi jumlah dan karakteristik poli asam laktat yang dihasilkan. Berdasarkan hasil penelitian, didapat konsentrasi $2 \%$ merupakan konsentrasi stanum yang paling optimum digunakan untuk menghasilkan poli asam laktat sebanyak 4,55 gram dengan bobot molekul 23289,83 g/mol dan residu katalis sebesar 175,174 ppm.

\section{B. Saran}

Perlu dilakukan penelitian lebih lanjut mengenai metode penghilangan residu katalis dalam poli asam laktat yang dihasilkan. Faktor lain yang dapat mempengaruhi proses polimerisasi juga perlu diteliti lebih lanjut, antara lain, pengaruh waktu, tekanan, jumlah xilena sebagai pelarut yang digunakan dan jenis katalis lain yang dapat menghasilkan poli asam laktat dengan jumlah optimum dan karakteristik yang diinginkan.

Tabel 1. Jumlah Poli Asam Laktat yang Dihasilkan Menurut Variasi Katalis.

\begin{tabular}{|c|c|c|c|c|c|c|c|c|c|c|c|}
\hline \multirow[b]{3}{*}{ Ulangan } & \multirow{3}{*}{$\begin{array}{r}\text { Konsentrasi } \\
\text { Stanum } \\
(\%)\end{array}$} & \multicolumn{10}{|c|}{ Jumlah Poli Asam Laktat yang Dihasilkan } \\
\hline & & \multicolumn{2}{|c|}{0} & \multicolumn{2}{|c|}{1} & \multicolumn{2}{|c|}{2} & \multicolumn{2}{|c|}{3} & \multicolumn{2}{|c|}{4} \\
\hline & & (g) & $(\%)$ & (g) & $(\%)$ & $(\mathrm{g})$ & $(\%)$ & $(\mathrm{g})$ & $(\%)$ & $(\mathrm{g})$ & $(\%)$ \\
\hline & 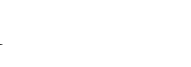 & 0 & 0 & 0 & 0 & 4,82 & 30,12 & 1,06 & 6,65 & 0 & 0 \\
\hline & 2 & 0 & 0 & 0 & 0 & 4,73 & 29,56 & 0,98 & 6,15 & 0 & 0 \\
\hline & 3 & 0 & 0 & 0 & 0 & 4,10 & 25,62 & 0,89 & 5,58 & 0 & 0 \\
\hline- & $\mathrm{K}$ & 0 & 0 & 0 & 0 & 4,55 & 28,44 & 0,98 & 6,15 & 0 & 0 \\
\hline
\end{tabular}

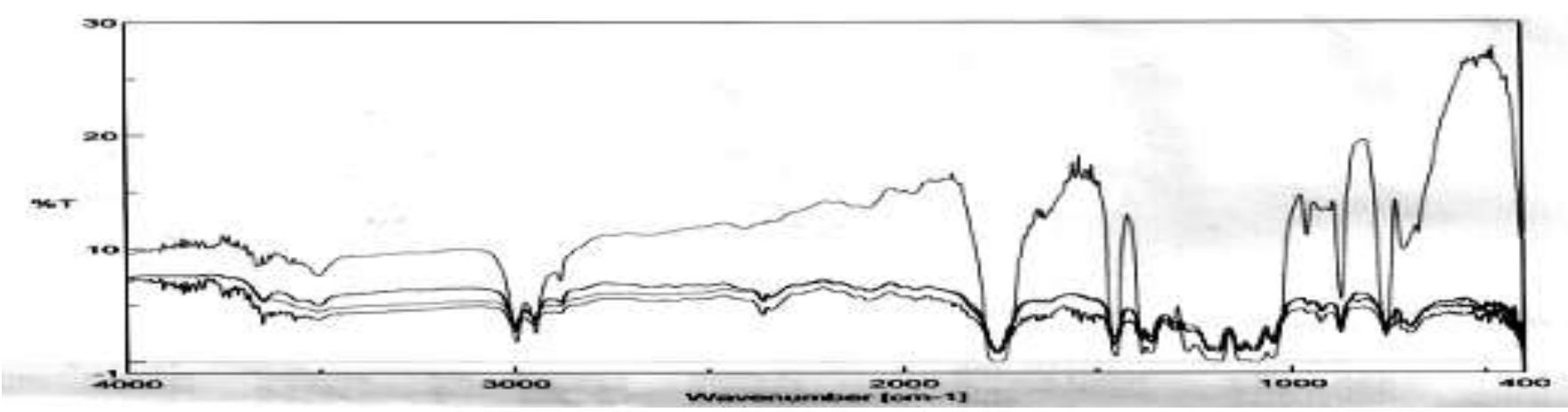

Gambar 2. Puncak Spektrum Infra Merah 
Tabel 2. Konsentrasi Stanum (ppm) dalam Poli Asam Laktat Hasil Sintesis.

\begin{tabular}{|c|c|c|c|c|c|c|}
\hline \multirow{3}{*}{ Ulangan } & \multicolumn{6}{|c|}{ Konsentrasi Stanum (ppm) } \\
\hline & \multicolumn{3}{|c|}{$2 \%$} & \multicolumn{3}{|c|}{$3 \%$} \\
\hline & 1 & 2 & 3 & 1 & 2 & 3 \\
\hline 1 & 173.4564 & 175.0100 & 176.9976 & 184.0439 & 188.0886 & 202.3161 \\
\hline 2 & 172.9856 & 175.4416 & 176.9830 & 183.8032 & 187.6512 & 200.1499 \\
\hline$-\bar{x}$ & 173.2210 & 175.2258 & 176.9903 & 183.9236 & 187.8699 & 201.2330 \\
\hline
\end{tabular}

\section{DAFTAR PUSTAKA}

Ajioka, M, K. Enomoto, K. Suzuki, dan A. Yamaguchi. 1995. "Basic Properties of Polylactic Acid Produced by the Direct Codensation Polymerization of Lactic Acid" dalam Bulletin of The Chemical Society of Japan. No.8. Volume 68. Chemical Society of Japan. Tokyo.

Ajioka, M. H. Suizu, C. Higuchi, dan T. Kashima. 1998. "Aliphatic Polyesters and Their Copolymers Synthesized through Direct Condensation Polymerization" dalam Polymer Degradation and Stability vol 59. Elsevier. Northern, Ireland.

Avérous, L. 2008. "Polylactic Acid : Synthesis, Properties and Applications" dalam Monomers, Polymers and Composites from Renewable Resources. Elsevier. Northern Ireland.

Dutkiewicz, S., D. G. Lapienis, dan W. Tomaszewski. 2003. "Synthesis of Poly(L(+) Lactic Acid) by Polycondensation Method in Solution" dalam FIBRES \& TEXTILES in Eastern Europe Vol. 11, No.4. Institute of Chemical Fibres. Poland.

Garlotta, D. 2002. "A Literature Review of Poly(Lactic Acid)" dalam Journal of Polymers and The Environment, Vol.9. Plenum Publishing Company. Tanpa Kota.

Nasiri, J. 2008. "Mengenal Polylactic Acid (PLA)" dalam Sentra Polimer vol. 27. Balai Pengkajian Teknologi Polimer-BPPT. Tangerang.

Lee, M. W., H. T. Tan, M. Chandrasekaran, dan C.P. Ooi. 2005. "Synthesis and Characterisation of PLLA by Melt Condensation using Binary Catalyst System" dalam SIMTech Technical Reports Vol.6, No. 3. Nanyang Technological University. Singapore.

Nurhayati, L. 2006. Aplikasi Mikrosfer Poli (Asam Laktat) sebagai Pengungkung Obat Selekoksib. IPB. Bogor. 